American Journal of Pharmacology and Toxicology 2 (1): 4-9, 2007

ISSN 1557-4962

(C) 2007 Science Publications

\title{
The Effect of Vitamin C on the Metabolic Parameters of Experimental Diabetes Mellitus
}

\author{
${ }^{1}$ Mariam Al-Shamsi, ${ }^{2}$ Amr Amin, ${ }^{3}$ Ernest Adeghate \\ ${ }^{1}$ Enviromental Graduate Program, ${ }^{2}$ Department of Biology, Faculty of Science \\ ${ }^{3}$ Department of Anatomy Faculty of Medicine and Health Sciences, UAE University \\ Al-Ain, UAE
}

\begin{abstract}
The role of vitamin $\mathrm{C}$ on diabetes mellitus is unknown. The purpose of this study was to examine the effect of oral administration of vitamin $\mathrm{C}$ on some of the metabolic parameters of diabetic rats. Diabetes was induced by intraperitoneal injection of STZ $\left(60 \mathrm{mg} \mathrm{kg}^{-1}\right.$ body weight at 12 weeks of age). Vitamin $\mathrm{C}\left(10,50,100 \mathrm{mg} \mathrm{kg}^{-1}\right.$ body weight) was administered orally for a period of four weeks to normal and diabetic male Wistar rats. In some experiments vitamin $\mathrm{C}$ was given either before or after the induction of diabetes mellitus. Glucose tolerance test (GTT) was performed on fasted normal, diabetic and vitamin C-treated rats at the end of the experimental period. Blood sugar level and weight were also recorded on a weekly basis for each rat in different groups. Vitamin $\mathrm{C}$ significantly $(\mathrm{p}<0.05)$ reduced blood glucose level and decreased weight gain in experimental diabetes mellitus at all doses when compared to untreated rats. This beneficial effect of vitamin $\mathrm{C}$ on the hyperglycemia of diabetic rats was dose-dependent. Moreover, vitamin $\mathrm{C}$ also improved GTT in diabetic rats compared to untreated diabetic rats. In conclusion, vitamin $\mathrm{C}$ may play a role in insulin metabolism and thus be a useful adjuvant therapy in diabetes mellitus.
\end{abstract}

Key words: ROS, vitamin C, antioxidants, diabetes, glucose

\section{INTRODUCTION}

Diabetes mellitus (DM) is currently taking its place as one of the main threats to human health in the $21^{\text {st }}$ century. In the past two decades the number of people with diabetes has increased worldwide. DM affects approximately $6 \%$ of the world population ${ }^{[1]}$. It is also one of the most prevalent (the estimated lifetime risk of developing diabetes for individuals born in 2000 is $32.8 \%$ for males and $38.5 \%$ for females) and costly chronic diseases, which significantly reduces life expectancy ${ }^{[2,3]}$. In the year 2000 , the total number of people with DM was 151 million and the number is projected to increase by $46 \%$ to reach 221 million by the year 2010 and 300 million in $2025^{[4]}$. DM is a heterogeneous group of disorders characterized by high blood glucose level ${ }^{[5]}$.

DM is associated with abnormal changes in protein, carbohydrate and fat metabolism ${ }^{[6]}$ and induce disturbances in lipid profiles especially, an increased susceptibility to lipid peroxidation ${ }^{[7]}$. DM is a chronic disease associated with severe late complications. Diabetes accounts for a substantial burden of morbidity and mortality through micro- and macro vascular complications $^{[8,9]}$. The most common chronic complications of diabetes include retinopathy, nephropathy, neuropathy and atherosclerosis ${ }^{[10]}$. Strict control of blood glucose, blood pressure and cholesterol can reduce the risk of diabetes-related complications ${ }^{[8,11]}$. It has been postulated that diabetesassociated complications involves oxidative stress perhaps as a result of hyperglycemia ${ }^{[12]}$. In diabetes, the elevated blood glucose increases the reactive oxygen species (ROS). ROS then causes membrane damage through facilitating peroxidation of membrane lipids and protein glycation ${ }^{[13,14]}$. The sources of ROS in diabetes include free radical reactions related to glycation of proteins, consumption of NADPH through the polyol pathway, glucose autoxidation, hyperglycemia-induced pseudo hypoxia and activation of protein kinase $C^{[15]}$. Vitamin $C$ is a water soluble antioxidant that was firstly isolated and characterized by Szent-Gyorgyi in $1928^{[16]}$. Ascorbic acid has several antioxidant properties. It is an essential cofactor involved in many biochemical functions and it acts as an electron donor or reducing agent, it is said to have ascorbate oxidant activity ${ }^{[17]}$. Ascorbate effectively scavenge singlet oxygen, superoxide, hydroxyl and water soluble peroxyl radical and hypochlorous acid ${ }^{[18]}$. The purpose of this study was to characterize some 
STZ-diabetic induced metabolic parameters as well as to examine the antioxidant effect of Vitamin $\mathrm{C}$ on diabetic rats.

\section{MATERIALS AND METHODS}

Experimental animals: Male Wistar rats aged from seven to eight weeks and weighing 200-300 g were used in this study. All rats were housed in a temperature $\left(25^{\circ} \mathrm{C}\right)$ and humidity controlled rooms with $12 \mathrm{hrs}$ light/dark cycles. The animals were fed on a standard rat chow and tap water ad libitum. Diabetes was induced in rats by a single intraperitoneal injection of streptozotocin (STZ, Sigma, St. Louis, Missouri, USA) at a dose of $60 \mathrm{mg} \mathrm{kg}^{-1}$ body weight ${ }^{[19]}$. STZ was dissolved immediately before use in $0.05 \mathrm{~mol} \mathrm{~L}^{-1}$ sodium citrate $(\mathrm{pH} 4.5)$. Blood was drawn from the tail vein and blood glucose was measured weekly using (One Touch II Glucometer, Life Scan, Johnson and Johnson, U.S.A.). Rats were considered diabetic only if their blood glucose levels exceeded $250 \mathrm{mg} \mathrm{dL}^{-1[20]}$. Rat body weights were also recorded on a weekly basis. The experiment was performed according the guidelines set by the Animal Ethics Committee, Faculty of Medicine \& Health Sciences, U.A.E. University.

Experimental design: Rats were randomly divided into three groups according to three different doses of vitamin $\mathrm{C}$ (low dose $10 \mathrm{mg} \mathrm{kg}^{-1}$, moderate dose $50 \mathrm{mg}$ $\mathrm{kg}^{-1}$ and high dose $100 \mathrm{mg} \mathrm{kg}^{-1}$ ). Each group was then divided into 5 subgroups. (a) Untreated non diabetic (control); where rats have not been treated with either STZ or vitamin C. (b) Untreated diabetic; STZ-induced diabetic rats that were not treated with vitamin $C$. (c) Treated diabetic; where rats were treated with vitamin C for 10 days prior the STZ-induction of diabetes. (d) Treated diabetic; where rats were induced to develop diabetes and 10 days later they were treated with vitamin C. (f) Treated non diabetic; in this subgroup, rats were treated with vitamin $\mathrm{C}$ only.

Glucose tolerance test (GTT): At the end of the four weeks from the commencement of the treatment, rats were subjected to a glucose tolerance test, after an overnight fast for $18 \mathrm{~h}$. On the day of the GTT the animals were given intraperitoneal dose of glucose 10 $\mathrm{mL} \mathrm{kg}^{-1}$ body weight, $30 \% \mathrm{w} / \mathrm{v}$. The blood glucose measurements were made at $0,30,60,120$ and $180 \mathrm{~min}$ after glucose challenge.

Statistical analysis: Data are expressed as mean \pm SD. Student's $t$-test was used to analyze the significance of differences between mean values and different groups were analyzed by analysis of variance using Duncan's multiple range tests. A $p$ value of less than 0.05 was considered statistically significant.

\section{RESULTS}

The oral administration of low dose $\left(10 \mathrm{mg} \mathrm{kg}^{-1}\right.$ body weight) of vitamin $\mathrm{C}$ to rats treated 10 days after the onset of diabetes resulted in weight gain compared to untreated diabetic rats which lost weight during the experimental period. This gain was still significantly smaller when compared to that of normal untreated and normal treated rats. Also, the weight gained by normal treated rats with low dose of vitamin $\mathrm{C}$ was still smaller compared to that of untreated normal rats. On the other hand, the administration of low dose of vitamin $\mathrm{C}$ to rats treated 10 days before the onset of diabetes resulted in high weight loss (Fig. 1).

Rat receiving a moderate dose $\left(50 \mathrm{mg} \mathrm{kg}^{-1}\right.$ body weight) of vitamin C 10 days after the onset of diabetes achieved lower weight gain compared to normal control.

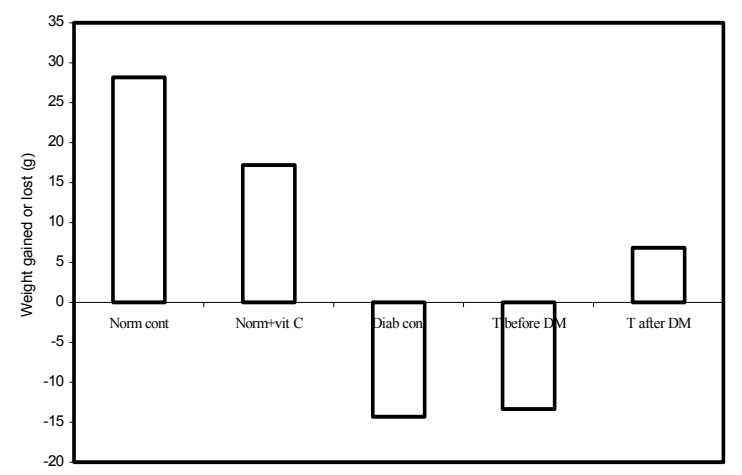

Fig. 1: Histograms showing the effect of $10 \mathrm{mg} \mathrm{kg}^{-1}$ body weight of vitamin $\mathrm{C}$ on weight gained or lost in normal and diabetic rats. (Data are mean $\pm \mathrm{SD}, \mathrm{n}=6) \mathrm{DM}=$ diabetes mellitus

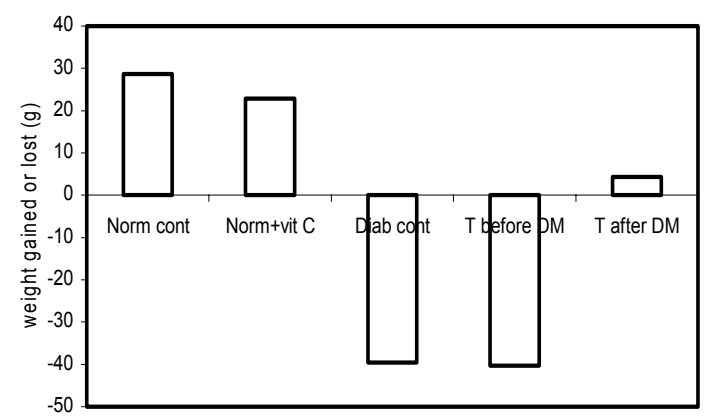

Fig. 2: Histograms showing the effect of $50 \mathrm{mg} \mathrm{kg}^{-1}$ body weight of vitamin $\mathrm{C}$ on weight gained or lost in normal and diabetic rats. (Data are mean $\pm \mathrm{SD}, \mathrm{n}=6) \mathrm{DM}=$ diabetes mellitus 
Am. J. Pharm. \& Toxicol., 2 (1): 4-9, 2007

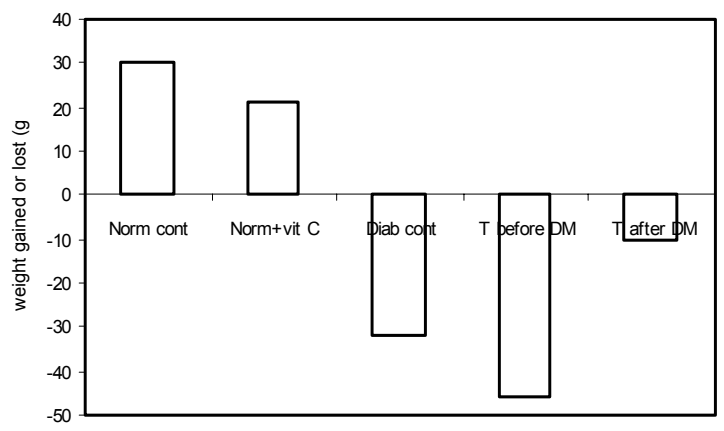

Fig. 3: Histograms showing the effect of $100 \mathrm{mg} \mathrm{kg}^{-1}$ body weight of vitamin $\mathrm{C}$ on weight gained or lost in normal and diabetic rats. (Data are mean $\pm \mathrm{SD}, \mathrm{n}=6$ ) $\mathrm{DM}=$ diabetes mellitus

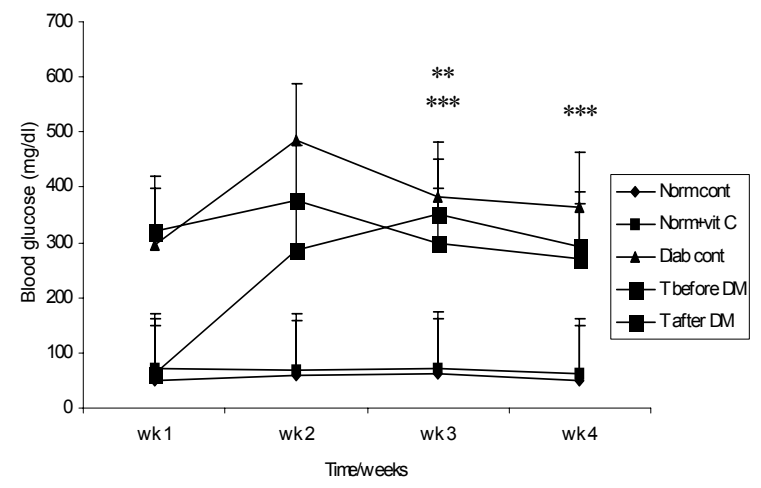

Fig. 4: Histograms showing the effect of $10 \mathrm{mg} \mathrm{kg}^{-1}$ of vitamin $\mathrm{C}$ on blood glucose level in normal and diabetic rats. In weeks 3 and 4 there was a significant difference in blood glucose level in normal non diabetic rats $* \mathrm{p}<0.05$ (norm cont versus norm + vitamin C). Also, there was a significant difference in blood glucose level in rats treated before the onset of DM rats in week $3 * * \mathrm{p}<0.05$ (diab cont versus treated before DM) and in rats treated after the onset of DM in weeks 3 and 4 $* * * \mathrm{p}<0.05$ (diab cont versus treated after DM) (Data are mean $\pm \mathrm{SD}, \mathrm{n}=6) \mathrm{DM}=$ diabetes mellitus

However, oral administration of moderate dose $(50 \mathrm{mg}$ $\mathrm{kg}^{-1}$ body weight) of vitamin $\mathrm{C}$ failed to increase the weight of normal rats compared to control (Fig. 2). The high dose (100 mg kg-1 body weight) of vitamin $\mathrm{C}$ given to diabetic rats also resulted in weight loss in both rats treated before and after the onset of diabetes. Normal rats, which received high dose of vitamin C failed to gain weight in the same rate as untreated normal rats (Fig. 3).

The oral administration of low dose $\left(10 \mathrm{mg} \mathrm{kg}^{-1}\right.$ body weight) of vitamin $\mathrm{C}$ reduced the level of blood glucose in rats treated before and after the onset of diabetes (Fig. 4).

Moreover, normal rats treated with low dose (10 $\mathrm{mg} \mathrm{kg}{ }^{-1}$ body weight) of vitamin $\mathrm{C}$ caused a significant decrease in blood glucose level when compared to normal untreated rats. The blood glucose level was

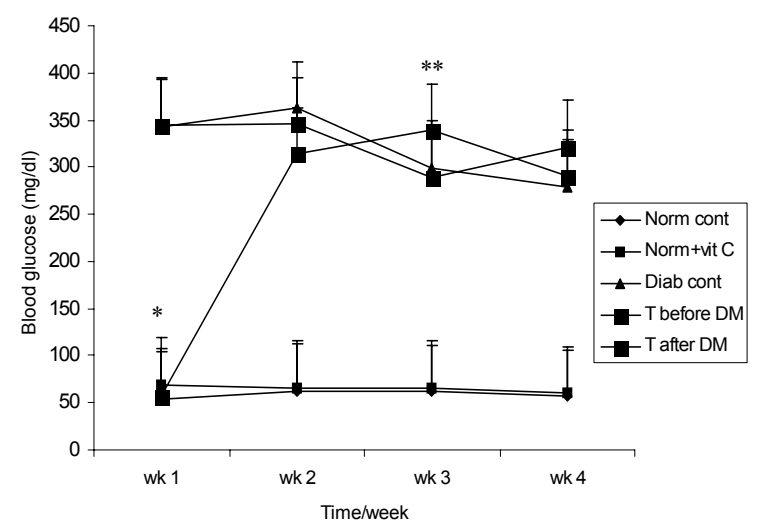

Fig. 5: Histograms showing the effect of $50 \mathrm{mg} \mathrm{kg}^{-1}$ of vitamin $\mathrm{C}$ on blood glucose level in normal and diabetic rats. In week 1 there was a significant difference in blood glucose level in normal control compared to treated non-diabetic rats $\left[{ }^{*} p<0.05\right.$ (norm cont versus norm + vitamin C)]. Also, there was a significant difference in blood glucose level in rats mellitus

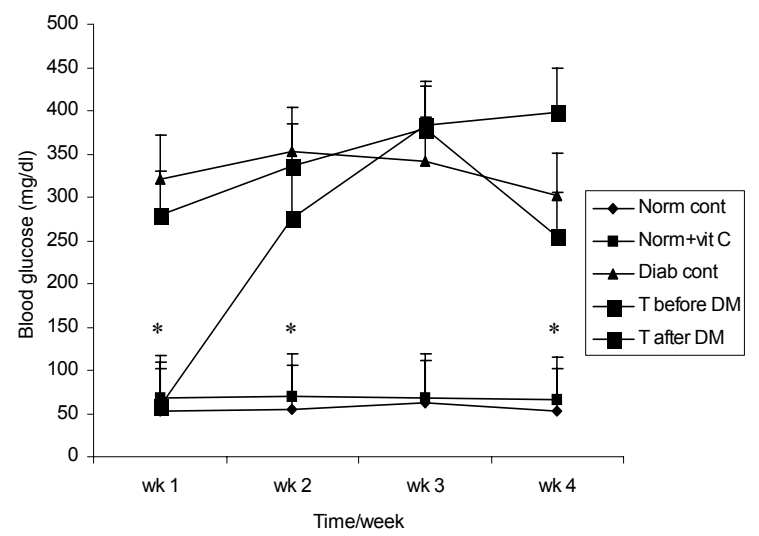

Fig. 6: Oral administration of high dose (100 $\mathrm{mg} \mathrm{kg}^{-1}$ body weight) of vitamin $\mathrm{C}$ failed to reduce blood glucose level in rats treated before and after the onset diabetes

slightly unchanged in diabetic rats treated with moderate dose $\left(50 \mathrm{mg} \mathrm{kg}^{-1}\right.$ body weight) of vitamin C after the onset of diabetes compared with untreated diabetic rats (Fig. 5). On the other hand, the level of blood glucose was significantly reduced compared with untreated normal rats. Figure 6 shows that the oral administration of high dose (100 $\mathrm{mg} \mathrm{kg}^{-1}$ body weight) of vitamin $\mathrm{C}$ failed to reduce blood glucose level in rats treated before and after the onset diabetes.

The GTT of rats that received vitamin C (10 mg $\mathrm{kg}^{-1}$ body weight) after the onset of diabetes was better than that of untreated diabetic rats. Rats that received low dose of vitamin $\mathrm{C}$ before and after the onset of diabetes had a better GTT at $60 \mathrm{~min}$ after glucose load compared to untreated diabetic rats (Fig. 7). The GTT of rats that received vitamin $\mathrm{C}\left(50 \mathrm{mg} \mathrm{kg}^{-1}\right.$ body 
Am. J. Pharm. \& Toxicol., 2 (1): 4-9, 2007

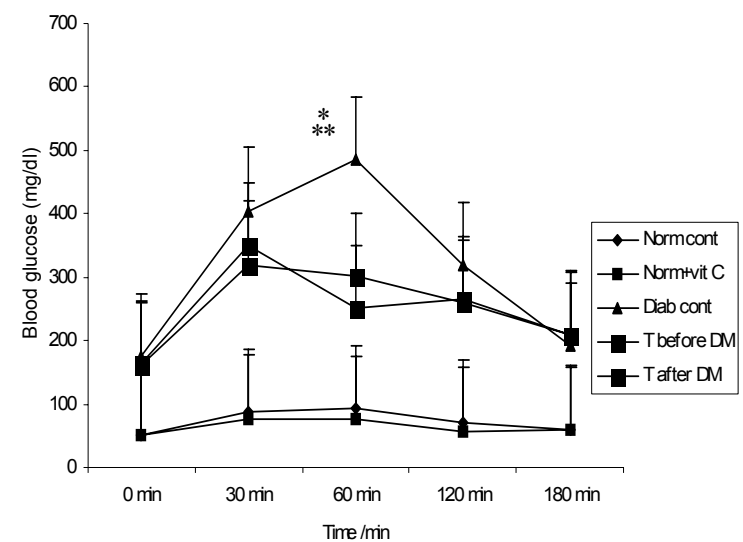

Fig. 7: Histograms showing the effect of $10 \mathrm{mg} \mathrm{kg}^{-1}$ of vitamin $\mathrm{C}$ on GTT in normal and diabetic rats. At 60 min there was a significant difference in blood glucose level in rats treated after the onset of DM $\left[{ }^{*} \mathrm{p}<0.05\right.$ (diab cont versus treated after DM)] and in rats treated before the onset of DM [**p $<0.05$ (diab cont versus treated before DM)] compared to untreated diabetic rats. (Data are mean $\pm \mathrm{SD}, \mathrm{n}=6$ ) $\mathrm{DM}=$ diabetes mellitus

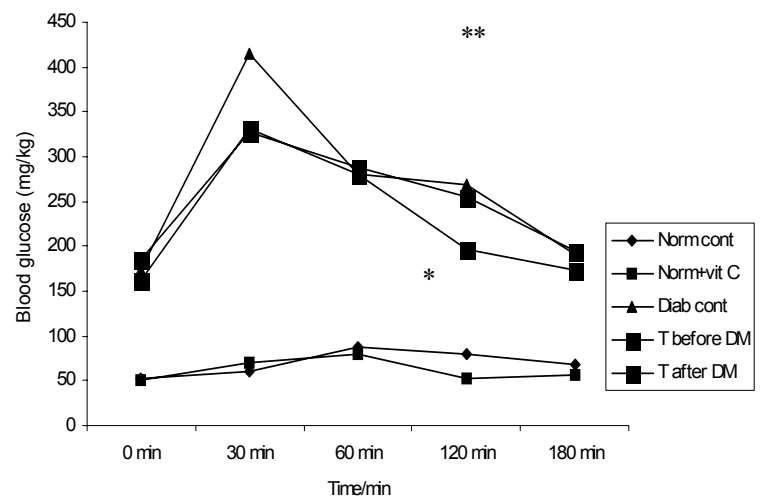

Fig. 8: Histograms showing the effect of $50 \mathrm{mg} \mathrm{kg}^{-1}$ of vitamin $\mathrm{C}$ on GTT in normal and diabetic rats. At 120 min there was a significant difference in blood glucose level in rats treated before the onset of DM rats $\left[{ }^{*} p<0.05\right.$ (diab cont versus treated before $\mathrm{DM})$ ] compared to diabetic controls and in normal non diabetic rats $[* * \mathrm{p}<0.05$ (norm cont versus norm+ vitamin C)] compared to vitamin C-treated rats. (Data are mean $\pm \mathrm{SD}, \mathrm{n}=6$ ) $\mathrm{DM}=$ diabetes mellitus

weight) before the onset of diabetes was better than that of untreated diabetic rats (Fig. 8). Moreover, the GTT of rats that received vitamin $\mathrm{C}$ before the onset of diabetes showed a significant reduction in the blood glucose level at $120 \mathrm{~min}$ after glucose challenge compared to untreated diabetic rats. However, it appeared that the GTT of rats that received vitamin C (50 $\mathrm{mg} \mathrm{kg}^{-1}$ body weight) before the onset of diabetes was better than that of rats that received vitamin $\mathrm{C}$ after the onset of diabetes. The GTT values of normal rats treated with vitamin $\mathrm{C}$ showed a significant reduction in

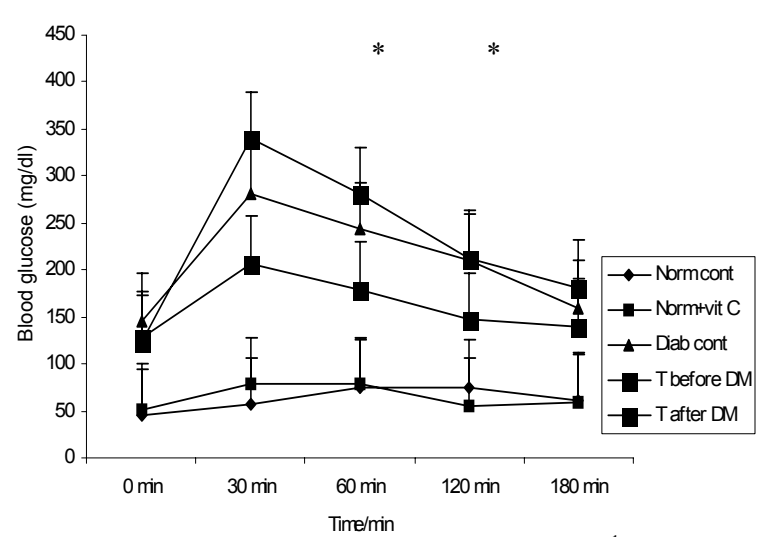

Fig. 9: Histograms showing the effect of $100 \mathrm{mg} \mathrm{kg}^{-1}$ of vitamin $\mathrm{C}$ on GTT of normal and diabetic rats. At 60 and 120 min there was a significant difference in blood glucose level in normal control compared to vitamin $\mathrm{C}$-treated rats $\left[{ }^{*} \mathrm{p}<0.05\right.$ (norm cont versus norm + vitamin $C)]$. (Data are mean $\pm S D, n=6)$ $\mathrm{DM}=$ diabetes mellitus

the blood glucose level at 120 min compared to that of untreated diabetic rats.

The GTT of rats that received high dose (100 mg $\mathrm{kg}^{-1}$ body weight) of vitamin $\mathrm{C}$ after the onset of diabetes was better than that of untreated diabetic rats (Fig. 9). However, the GTT of rats that received vitamin $\mathrm{C}$ after the onset of diabetes was better at 60 and $120 \mathrm{~min}$ after glucose challenge compared to that of untreated diabetic rats. The GTT values of normal rats treated with vitamin $\mathrm{C}$ was comparable to that of untreated normal rats.

\section{DISCUSSION}

The present study showed that the administration of vitamin $\mathrm{C}$ has an inverse correlation with body weight gain in rats treated 10 days before the onset of diabetes. Low dose of vitamin $\mathrm{C}$ can elevate body weight gain in rats treated 10 days after the onset of diabetes. Moderate dose also increased body weight gain in a rate smaller than that of low dose. However, high dose decreased body weight gain in rats treated 10 days after onset of DM. This observation suggested that only the low dose of vitamin $\mathrm{C}$ has a beneficial effect on diabetes and the moderate and high doses had an adverse effect on body weight gain especially after the onset of diabetes. Also, the administration of vitamin C in rats before the onset of diabetes did not reduce the effect of the diabetes on the body weight. Further studies are required to establish the mechanism of action of vitamin $\mathrm{C}$ on body weight. The mechanism by which vitamin $\mathrm{C}$ reduces body weight in normal rats is 
not clear. Levels of liver enzymes, kidney parameters and electrolytes have been reported to alter during STZinduced diabetes. Vitamin $\mathrm{C}$ has been shown to affect these biochemical parameters both in normal and diabetic rats ${ }^{[21]}$.

The present study also showed that vitamin $\mathrm{C}$ can improve plasma glucose level. The administration of low dose of vitamin $\mathrm{C}$ was more effective than that of moderate and high doses. It significantly reduced the plasma glucose level in rats treated 10 days before and after the onset of diabetes. Also, vitamin C supplementation significantly elevated glucose level in non diabetic rats. It is not clear how vitamin $\mathrm{C}$ improves blood glucose level in diabetic rats. This effect may be due to the antioxidant property of vitamin $\mathrm{C}$.

The data from this study showed that low dose of vitamin $\mathrm{C}$ significantly improved the glucose tolerance in rats treated 10 days before and after the onset of diabetes especially at $60 \mathrm{~min}$. On the other hand, administration of high dose of vitamin $\mathrm{C}$ significantly reduced glucose level at 60 and 120 min only in rats treated 10 days after the onset of diabetes. The beneficial effect of ascorbic acid noted in the present study can be attributed to the antioxidant effects of vitamin $\mathrm{C}$. Vitamin $\mathrm{C}$ is a scavenger of oxygen free radicals which are toxic by-products of many metabolic process and in STZ-induced diabetes. Free radicals have been reported in the pathogenesis of diabetes as a result of their severe cytotoxic effects, such as lipid peroxidation and protein denaturation of the cell membrane followed by alteration of the membrane receptor and fluidity properties ${ }^{[22,23]}$. In addition, high glucose level was shown to downregulate the expression of glucose transporter 1 (GLUT-1). The high glucose-induced downregulation of GLUT-1 was shown to be blocked by Akt inhibitors. Normally, the high glucose is known to activate Akt. Antioxidants such as vitamin $\mathrm{C}$ and catalase have been reported to block the high glucose-induced phosphorylation of $\mathrm{Akt}^{[24]}$.

\section{CONCLUSION}

It can be concluded from this study that the administration of vitamin $\mathrm{C}$ to normal and STZ-induced diabetic rats significantly decreased body weight gain in a dose-correlated manner. The oral administration of vitamin $\mathrm{C}$ also, reduced blood glucose level and improved glucose tolerance. The result of obtained from this study have provided insight into the hypoglycemic effect of vitamin $\mathrm{C}$ and it may prove to be a useful adjuvant therapy in the management of diabetes mellitus.

\section{REFERENCES}

1. Adeghate, E., 1999. Effect of subcutaneous pancreatic tissue transplants on streptozotocin induced diabetes in rats. Tissue Cell, 31: 73-83.

2. Adeghate, E., 2001. Diabetes mellitusmultifactorial in aetiology and global in prevalence. Arch. Physiol. Biochem., 109: 197199.

3. Bell, G. I., and K.S. Polonsky, 2001. Diabetes mellitus and genetically programmed defects in Bcell function. Nature, 13: 788-791.

4. Brownlee, M., 2001. Biochemistry and molecular cell biology of diabetic complications. Nature, 414: 813-820.

5. Canepa, E.T., E.B.C. Llambias and M. Grinstein, 1990. Studies on regulatory mechanisms of heme biosynthesis in hepatocytes from normal and experimentaldiabetic rats: Role of insulin. Biochem. Cell Biol., 689: 14-921.

6. Dominique, L.M.E., H. Betan, H. Larsen and S.P. Lawerence, 2003. Relationship of depression to diabetes types 1 and 2: Epidemiology, biology and treatment. Biol. Psychiat., 54: 317-329.

7. Drisko, J.A.J., J. Chapman and V.J. Hunter, 2003. The use of antioxidant therapies during chemotherapy. Gynecol. Oncol., 88: 434-439.

8. Gaede, P., P. Vedal and N. Larsen, 2003. Multifactorial intervention and cardiovascular disease in patients with type 2 diabetes. N. Engl. J. Med., 348: 383-393.

9. Heymann, A.D., G. Chodick, H. Halkin, A. Karasik, V. Shalev, J. Shemer and A. Kokia, 2006. The implementation of managed care for diabetes using medical informatics in a large preferred provider organization. Diab. Res. Clin. Pract., 71: 290-298.

10. Hunt, J.V., C.C.T. Smith and S.P. Wolff, 1990. Auto-oxidative glycosylation and possible involvement of peroxides and free radicals in LDL modification by glucose. Diabetes, 39: 1420-1424.

11. Kikkawa, R., 2000. Chronic complications in diabetes mellitus. Brit. J. Nutr., 84: S183-S185.

12. Mahadik, S.P., D. Evans and L. Harbans, 2001. Oxidative stress and role of antioxidant and 3 essential fatty acid supplementation in schizophrenia. Prog. Neuro-Psychoph., 25: 463- 493.

13. Narayan, K.M., J.P. Boyle, T.J. Thompson, S.W. Sorensen and D.F. Williamson, 2003. Lifetime risk for diabetes mellitus in the United States. JAMA, 290: 1884-1890. 
14. Pacher, P. and C. Szabó, 2006. Role of peroxynitrite in the pathogenesis of cardiovascular complications of diabetes. Curr. Opin. Pharmacol., 6: 136-141.

15. Rice, M.E., 2000. Ascorbate regulation and its neuroprotective role in the brain. Trends Neurosci., 23: 209-216.

16. Sato, Y., N. Hotto, N. Sakamoto, S. Matsuoka, N. Ohishi and K. Yafi, 1979. Lipid peroxide level in plasma of diabetic patients. Biochem. Med., 2: 104-107.

17. Sedhrouchni, I., J. Drai, E. Bammier, J. Riviere, P. Calmard, I. Garcia, J. Orgiazzi and A. Revol, 2002. Oxidative stress parameters in type I, type II and insulin- treated type 2 diabetes mellitus; insulin treatment efficiency. Clin. Chim. Acta, 321: 89-96.

18. Smirnoff, N. and G.L. Wheeler, , 2000. Ascorbic acid in plants: Biosynthesis and function. Crit. Rev. Biochem. Mol. Biol., 35: 291-314.

19. Vijayakumar, M., R. Govindarajan, G.M.M. Rao, Ch.V. Rao, A. Shirwaikar, S. Mehrotra and P. Pushpangadan, 2006. Action of Hygrophila auriculata against streptozotocininduced oxidative stress. J. Ethnopharmacol., 104: 356-361.
20. Zimmet, P., K.G.M. Alberti and J. Shaoo, 2001. Global and societal implications of the diabetes epidemic. Nature, 414: 782-787.

21. Al-Shamsi, M.A., A. Amin and E. Adeghate, 2006. Effect of vitamin $C$ on liver and kidney functions in normal and diabetic rats. Ann. N.Y. Acad. Sci., 1084: 371-90.

22. Gupta, M.M. and S. Chari, 2005. Lipid peroxidation and antioxidant status in patients with diabetic retinopathy. Ind. J. Physiol. Pharmacol., 49: 187-92.

23. Manea, A., E. Constantinescu, D. Popov and M. Raicu, 2004. Changes in oxidative balance in rat pericytes exposed to diabetic conditions. J. Cell. Mol. Med., 8: 117-26.

24. Kim, D.-I., S.-K. Lim, M.-J. Park, H.-J. Han, G.-Y. Kim and S.H. Park, 2006. The involvement of phosphatidylinositol 3-kinase /Akt signaling in high glucose-induced downregulation of GLUT-1 expression in ARPE cells. Life Sciences, November, 2006. 